\title{
PLACING A BILIARY STENT UNDER INTRAOPERATIVE ULTRASOUND CONTROL IN PRIMARY AND SECONDARY HEPATIC CARCINOMA
}

\author{
Ivaylo Vazharov \\ Department of Gastroenterology, Naval Hospital of Varna, \\ Military Medical Academy of Sofia
}

\begin{abstract}
PURPOSE: To explore the opportunities to place a biliary stent under intraoperative ultrasound control in primary and secondary hepatic carcinoma.

MATERIAL AND METHODS: We used ultrasound apparatus Aloka SDD 4000+ provided with USTMC11-8731 Aloka ultrasound electronic convex intraoperative transducer for this ultrasound-guided manipulation. We placed a biliary stent in 12 patients. Of them, five patients presented with primary hepatic carcinoma and seven ones with metastatic hepatic disease.

RESULTS: This manipulation was carried out under ultrasound control in cases of inoperability and mechanical jaundice because of hepatic malignancies.

CONCLUSION: Biliary stent placement under ultrasound control because of inoperability and mechanical jaundice in primary and secondary hepatic carcinoma is an effective interventional procedure. It can be performed easily and safely.
\end{abstract}

Key words: primary hepatic tumour, liver metastases, intraoperative ultrasound, ultrasound-guided manipulation, biliary stent

\section{INTRODUCTION}

Intraoperative ultrasound is used in the operative treatment of primary and secondary hepatic tumours since the 70 's of the $20^{\text {th }}$ century onwards (2). Intraoperative ultrasound can detect additional lesions, especially in metastatic neoplasms (1), it alters the surgical strategy in some patients (5) and helps preserving the hepatic parenchyma. When

Address for correspondence:

Ivaylo Vazharov, MD, PhD

Department of Gastroenterology,

Naval Hospital of Varna,

Military Medical Academy of Sofia

3 Hristo Smirnenski Str.

9010 Varna, Bulgaria

E-mail:vajarov@dir.bg

Received: November 28, 2012

Accepted: January 15, 2013 the operation is radical, this method defines the interrelations between the tumour and the vascular network (3). Along with these opportunities, intraoperative ultrasound enables the performance of the intraoperative manipulations under ultrasound control (4).

In this article, we share our own experience of placing the biliary stent under the control of intraoperative ultrasound in patients with primary or secondary hepatic malignancy.

\section{MATERIAL AND METHODS}

We used ultrasound apparatus Aloka SDD $4000+$ provided with UST-MC11-8731 Aloka ultrasound electronic convex intraoperative transducer for this ultrasound-guided manipulation.

We placed a biliary stent in 12 patients. Of them, five patients presented with primary hepatic 
carcinoma and seven ones with metastatic hepatic disease.

The manipulation was carried out under ultrasound control in cases of inoperability and mechanical icterus in hepatic malignancies.

\section{RESULTS}

We performed the examination in the following way. We found the dilated biliary duct with intraoperative ultrasound first, which was above a branch of the portal vein to avoid a haemorrhage. After that we measured the distance to the surface of the liver (Fig. 1 and Fig. 4). We introduced the stent in the biliary duct under ultrasound control (Fig. 2, Fig. 5, Fig. 7 and Fig. 8). A contrast cholangiography through the stent could be performed after the

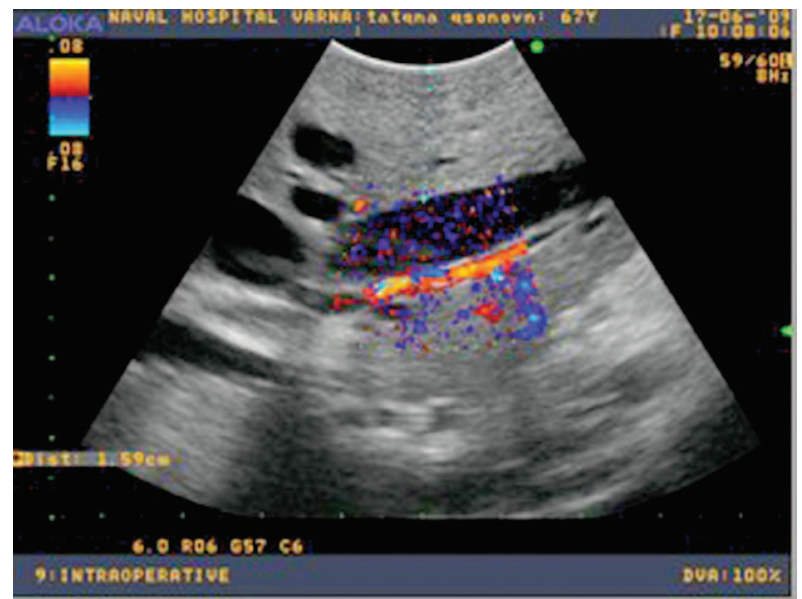

Fig. 1. Initial stages of stent placement

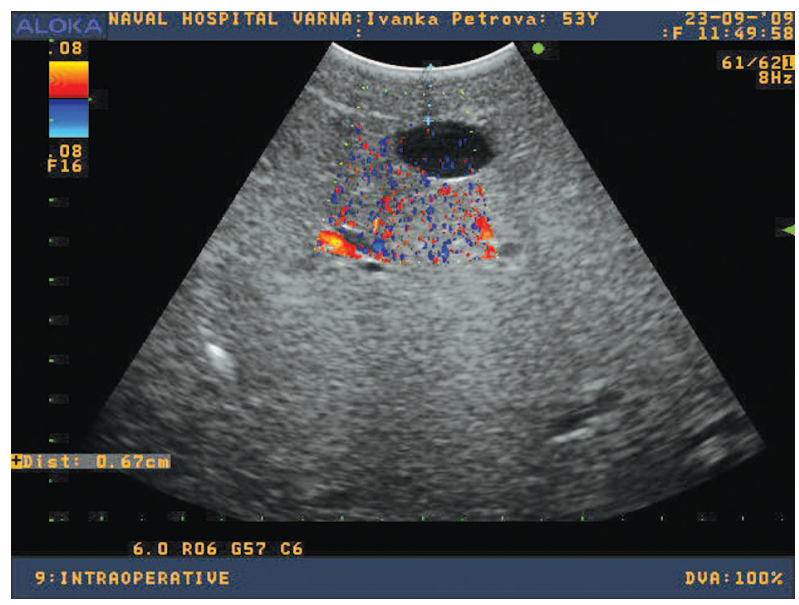

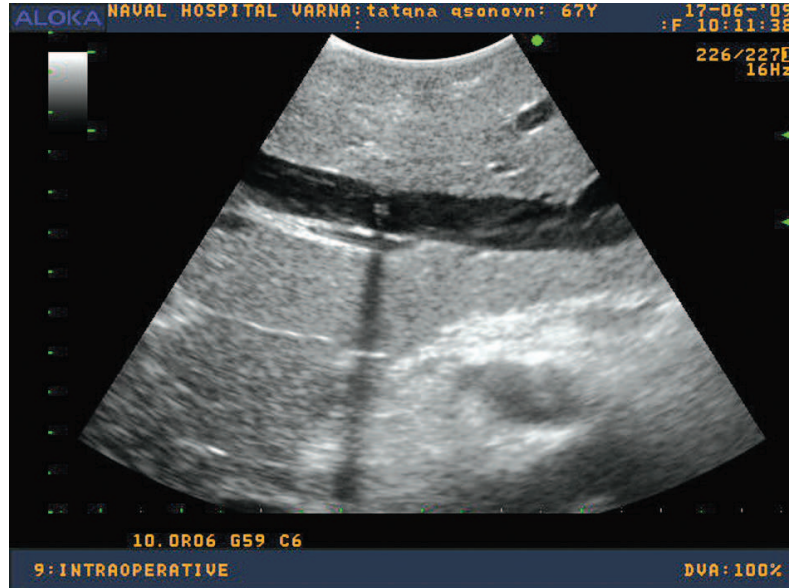

Fig. 2. The stent is in ductus hepaticus. The tip of the guiding device gives ultrasound shadow

manipulation (Fig. 3). So, we could control the stent postoperatively by means of percutaneous

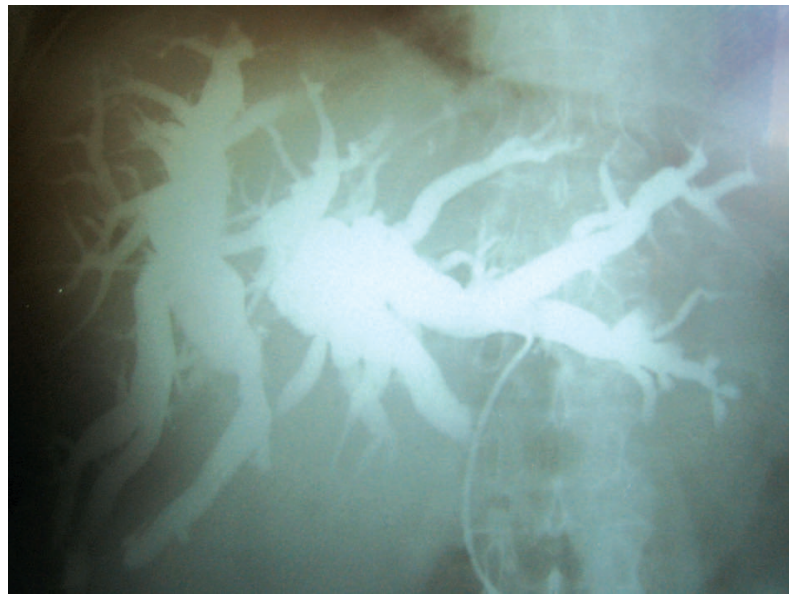

Fig. 3. Contrast cholangiography after the manipulation

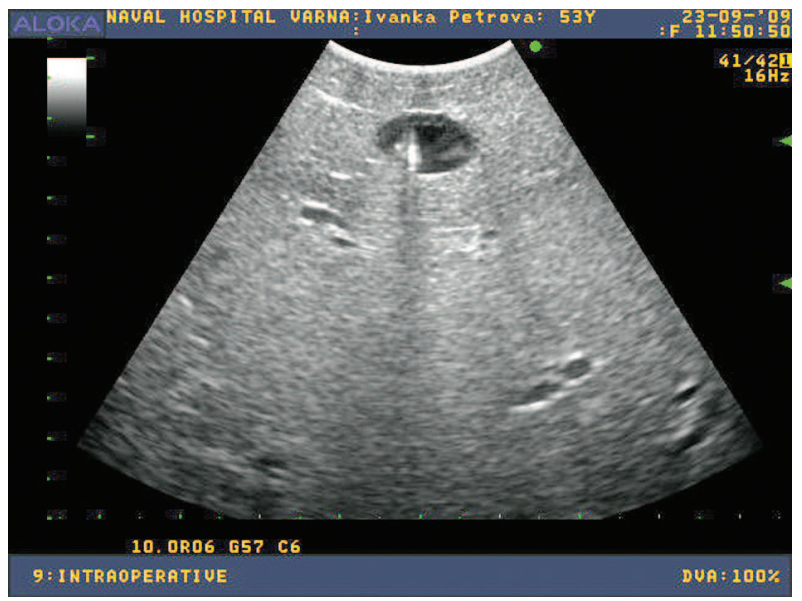

Fig. 4 \& Fig. 5. The same manipulation in another female patient 


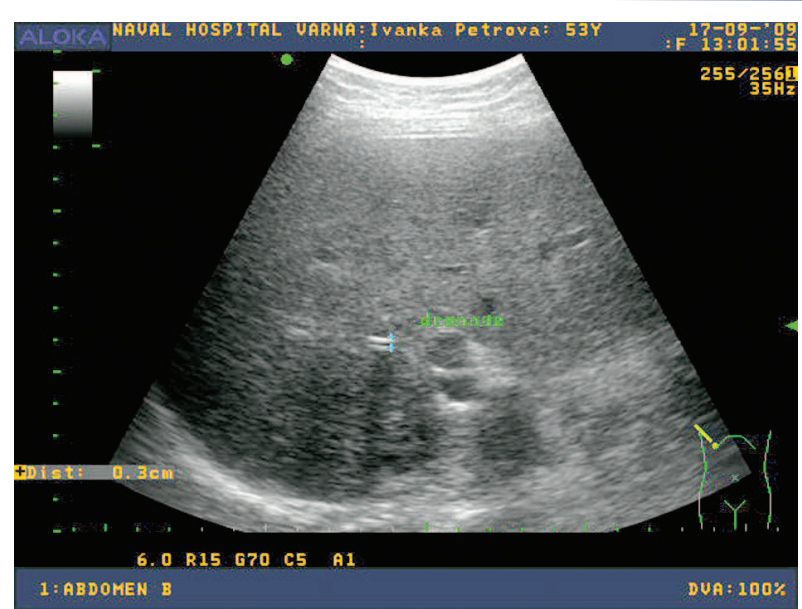

Fig. 6. Postoperative controlling the stent by means of ultrasound

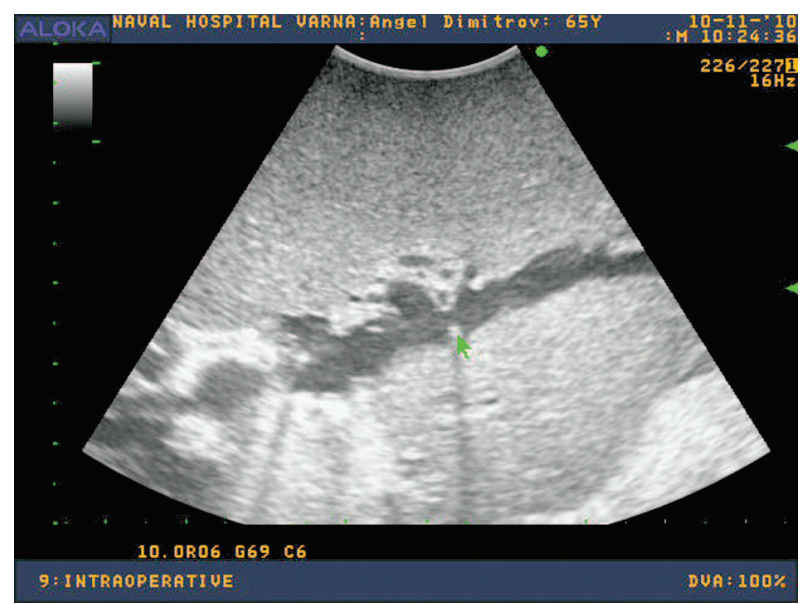

\section{REFERENCES}

1. Conlon, R., M. Jacobs, D. Dasgupta, J. P. Lodge. The value of intraoperative ultrasound during hepatic resection compared with improved preoperative magnetic resonance imaging.- Eur. J. Ultrasound, 16, 2003, No 3, 211-216.

2. Makuuchi, M., K. Kamiya, M. Sugiura, et al. Ultrasonic examination by electronic scanning during operation.- In: Proceedings of the $32^{\text {nd }}$ Meeting of the Japan Society of Ultrasonics in Medicine. 1977, 129-130.

3. Makuuchi, M., G. Torzilli, J. Machi. History of intraoperative ultrasound.- Ultrasound Med. Biol., 24, 1998, No 9, 1229-1242.

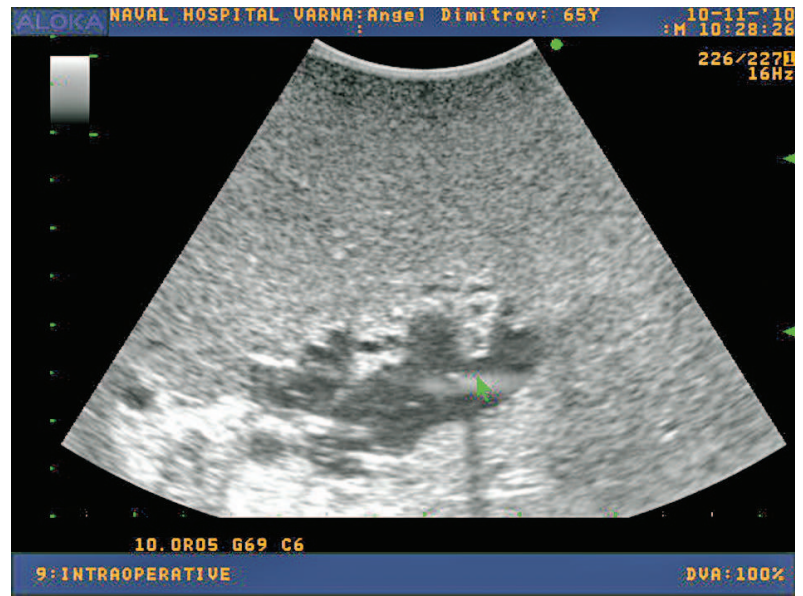

Fig. 7 \& Fig. 8. Biliary stent placeemnt in the left ductus hepaticus in a third patient. The arrow points the tip of the guiding device and gives ultrasound shadow in the biliary duct

ultrasound examination (Fig. 6). There were no side effects following the examination of the patients.

\section{CONCLUSION}

Biliary stent placement under ultrasound control because of inoperability and mechanical jaundice in primary and secondary hepatic carcinoma is an interventional procedure which can be performed easily and safely.
4. Torzilli, G., M. Makuuchi. Intraoperative ultrasonography in liver cancer.- Surg. Oncol. Clin. North Am., 12, 2003, No 1, 91-103.

5. Wildi, S. M., C. Gubler, T. Hany, H. Petrowsky, P. A. Clavien, W. Jochum, et al. Intraoperative sonography in patients with colorectal cancer and resectable liver metastases on preoperative FDGPET-CT.- J. Clin. Ultrasound, 36, 2008, No 1, 20-26. 